\section{Safety and predictability of conscious sedation in dentistry - a multi-centre regional audit: South and West Wales experience}

\author{
A. Muthukrishnan, ${ }^{* 1}$ J. McGregor ${ }^{2}$ and S. Thompson ${ }^{3}$
}

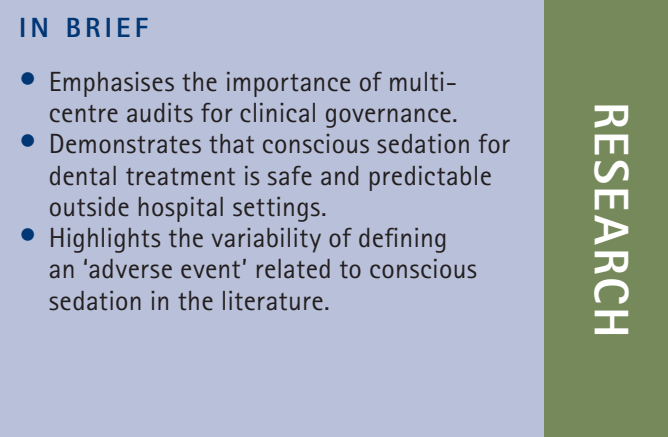

\begin{abstract}
Introduction There are no previously published reports of audits in conscious sedation from a group comprising the general dental services (GDS), community dental services (CDS) and hospital dental services (HDS). Aim The main aim of this audit was to assess current practice within the group in relation to the safety and predictability of dental treatment undertaken with the aid of conscious sedation. Methods A total of nine centres collected data prospectively on 1,037 sedation episodes over the course of one year. Audit standards were locally agreed based on current evidence and local experience. They were set at a completion rate of $90 \%$ and an adverse incident rate of $2 \%$ or less. Results Based on the data collected, a completion rate of $92 \%$ and a minor adverse incident rate of $2.6 \%$ were recorded. Conclusions The participating centres met the standards set locally for this audit. Current practice in the participating centres was found to be safe and predictable. The audit tool is being refined to improve the quality of data collection. Further research and service evaluation is recommended.
\end{abstract}

\section{INTRODUCTION}

Conscious sedation is defined as 'a technique in which the use of a drug or drugs produces a state of depression of the central nervous system enabling treatment to be carried out, but during which verbal contact with the patient is maintained throughout the period of sedation. The drugs and techniques used to provide conscious sedation for dental treatment should carry a margin of safety wide enough to render loss of consciousness unlikely.

This definition is accepted by the Standing Dental Advisory Committee (SDAC), ${ }^{1}$ the Scottish Dental Clinical Effectiveness Programme (SDCEP), ${ }^{2}$ the Dental Sedation Teachers Group (DSTG) ${ }^{3}$ and the Department of Health. ${ }^{4}$

\footnotetext{
'Associate Specialist, Dept of Restorative

Dentistry, Morriston Hospital, Swansea, SA6 6NL; ${ }^{2}$ Quality and Audit Coordinator, Dental Division, University Dental Hospital, Cardiff, CF14 4XY;

${ }^{3} \mathrm{~S} c h o o l$ of Dentistry, College of Biomedical and Life Sciences, Cardiff University, CF14 4XY ${ }^{*}$ Correspondence to: Akhila Muthukrishnan Email:akhila30@aol.com
}

\section{Online article number E13}

Refereed Paper - accepted 3 June 2013

DOI: 10.1038/sj.bdj.992

${ }^{\circledR}$ British Dental Journal 2013; 215: E13
Few studies have assessed the rate of completion of dental treatment with the adjunctive use of conscious sedation. In a study of 265 children receiving dental treatment using inhalation sedation (IHS) and local anaesthesia, Blain and Hill (1998) reported an overall completion rate of $84 \% .{ }^{5}$ Wood (2011) in a prospective study of 114 children using intra-nasal sedation (INS) reported a completion rate of 91\%. Manley et al. (2008) reported a completion rate of nearly $92 \%$ based on a combination of intra-nasal sedation (INS) and intravenous sedation (IVS) in 222 sedation episodes. ${ }^{7}$

In the literature there are various reports on the incidence of adverse events in sedation. ${ }^{8,9,10}$ However, closer analysis reveals that the majority of these events were not related to the practice of conscious sedation, as defined in the UK. ${ }^{1-4}$

\section{AIM}

The primary aim of this audit was to assess current practice within the group comprising the general dental services (GDS), community dental services (CDS) and hospital dental services (HDS) in relation to the safety and predictability of dental treatment with the aid of conscious sedation. A secondary aim was to establish a network of sedation practitioners across the dental services in South and West Wales to facilitate research and clinical governance. Through this process, it was proposed to establish a baseline of current practice in relation to conscious sedation in South and West Wales. This would also help to inform commissioners on the safety and efficacy of conscious sedation in dentistry.

\section{METHODS}

The audit followed the cycle of setting a standard, collecting data regarding current practice, comparing current practice against the standard and implementing changes where needed. ${ }^{11}$

A preliminary meeting was arranged to discuss the setting up of a network. This was coordinated by one sedation practitioner (AM). Practitioners who were known to undertake conscious sedation in the GDS, CDS and HDS were invited to the preliminary meeting. Discussion among the initial group suggested the need to establish a baseline of current practice prospectively. Other practitioners who had not been identified initially were also invited to join the network by phone, email and personal contact. A total of nine centres agreed to participate in this audit. 


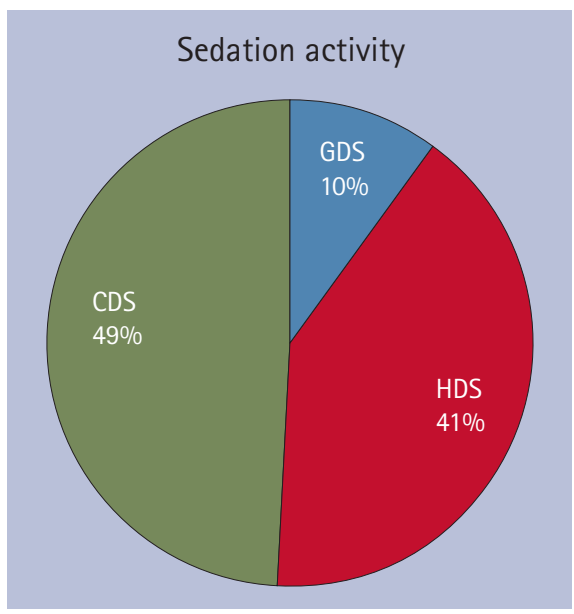

Fig. 1 Distribution across the services

A literature search was conducted using Medline, OVID, and Google Scholar. This identified previous audits and research studies to provide comparative standards for completion rate for dental treatment with conscious sedation., ${ }^{5,6,7}$ The standard for completion rate for this audit was set at 90\%.

Good quality research studies on the safety of midazolam are very limited and usually focus on clinical efficacy rather than patient safety. A standard of an adverse incident rate not exceeding $2 \%$ was therefore agreed locally, based on the collective experience of the group.

Each practitioner filled out the data sheet at the time of the corresponding appointment for treatment with sedation. All types of sedation were included for the purpose of this audit. It was assumed that the patient's medical history and dental treatment plan had already been checked during the initial assessment appointment. Therefore, this information was not recorded in the spreadsheet. A prototype of a data collection spreadsheet was made available to the members of the network by the coordinator. Individual practitioners adapted it for local use, when needed.

The following categories were mandatory for inclusion in the results:

- Site code

- Age

- Sex

- Patient ID number

- Type of sedation

- American Society of Anaesthesiology (ASA) status

- Completion of treatment (Y/N and details)

- Adverse incident/s (Y/N and details)

- Advised to fast before sedation $(\mathrm{Y} / \mathrm{N})$.

Table 1 Number of sedation episodes by centre

\begin{tabular}{l|l|l|l|l|l|l|l|l|l} 
Centre & 1 & 2 & 3 & 4 & 5 & 6 & 7 & 8 & 9 \\
\hline No. of sedation episodes & 308 & 51 & 84 & 101 & 126 & 10 & 241 & 70 & 46 \\
\hline
\end{tabular}

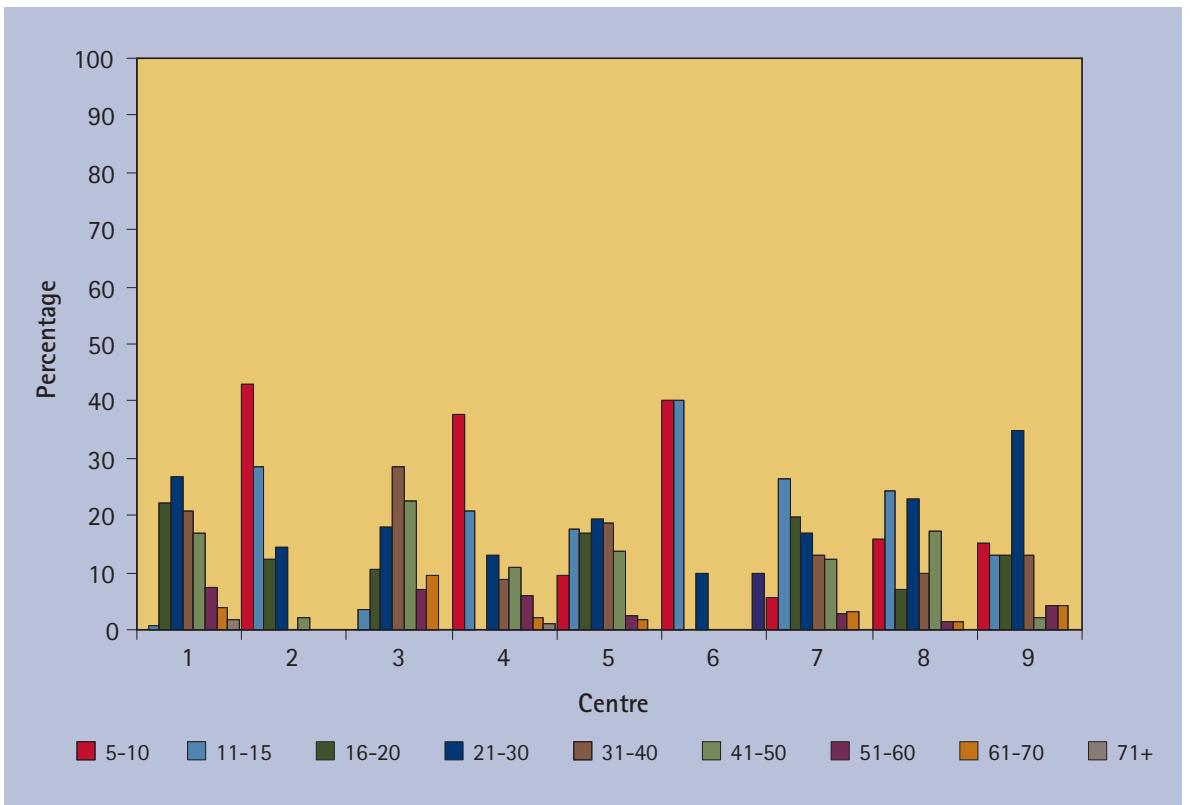

Fig. 2 Age group

Practitioners also had the option of recording:

- Body mass index (BMI)

- Pulse recorded $(\mathrm{Y} / \mathrm{N})$

- Blood pressure recorded $(\mathrm{Y} / \mathrm{N})$

- Additional drugs used $(\mathrm{Y} / \mathrm{N})$

- Patient satisfaction score

- Modified dental anxiety score (MDAS)

- Percentage of N20 used (\%)

- Dosage of midazolam used (mg)

- Flumazenil use (Y/N).

Some practitioners already had their own spreadsheets for data collection as part of their local clinical governance arrangements. The members of the network had the choice to use their own spreadsheets, as long as the required data could be collected. The coordinator (AM) communicated with the members of the network regularly to ensure data collection. A deadline was set for one year for the analysis of the preliminary data. A second meeting was held in the early part of the data collection phase, in order to identify any issues noted by the participants. A third meeting was held on completion of the audit to discuss any issues with the data collection.

Individual results were anonymised in the final collective analysis and identified by a code or origin. The identity of the individual results was known only to two authors - the coordinator (AM) and the quality and audit officer (JM). Individual results were made available only to the respective practitioners and not to the whole group. For the purpose of this prospective audit, the focus was on safety and predictability.

All nine centres submitted their data for analysis. Data were analysed by one of the authors (JM) from the Quality and Audit Department at Cardiff and Vale University Health Board.

\section{RESULTS}

Data were collected from each of the nine centres for a total of 1,037 sedation episodes over one year.

\section{Distribution of sedation activity across the dental services}

The distribution of the sedation episodes is illustrated on Table 1. Overall, the group consisted of two hospital centres; one of which was a teaching hospital. In addition, there was one GDS centre which had a contract with the Local Health Board to provide sedation services. The remaining centres were within the CDS. The majority of the treatment (52\%) was undertaken 


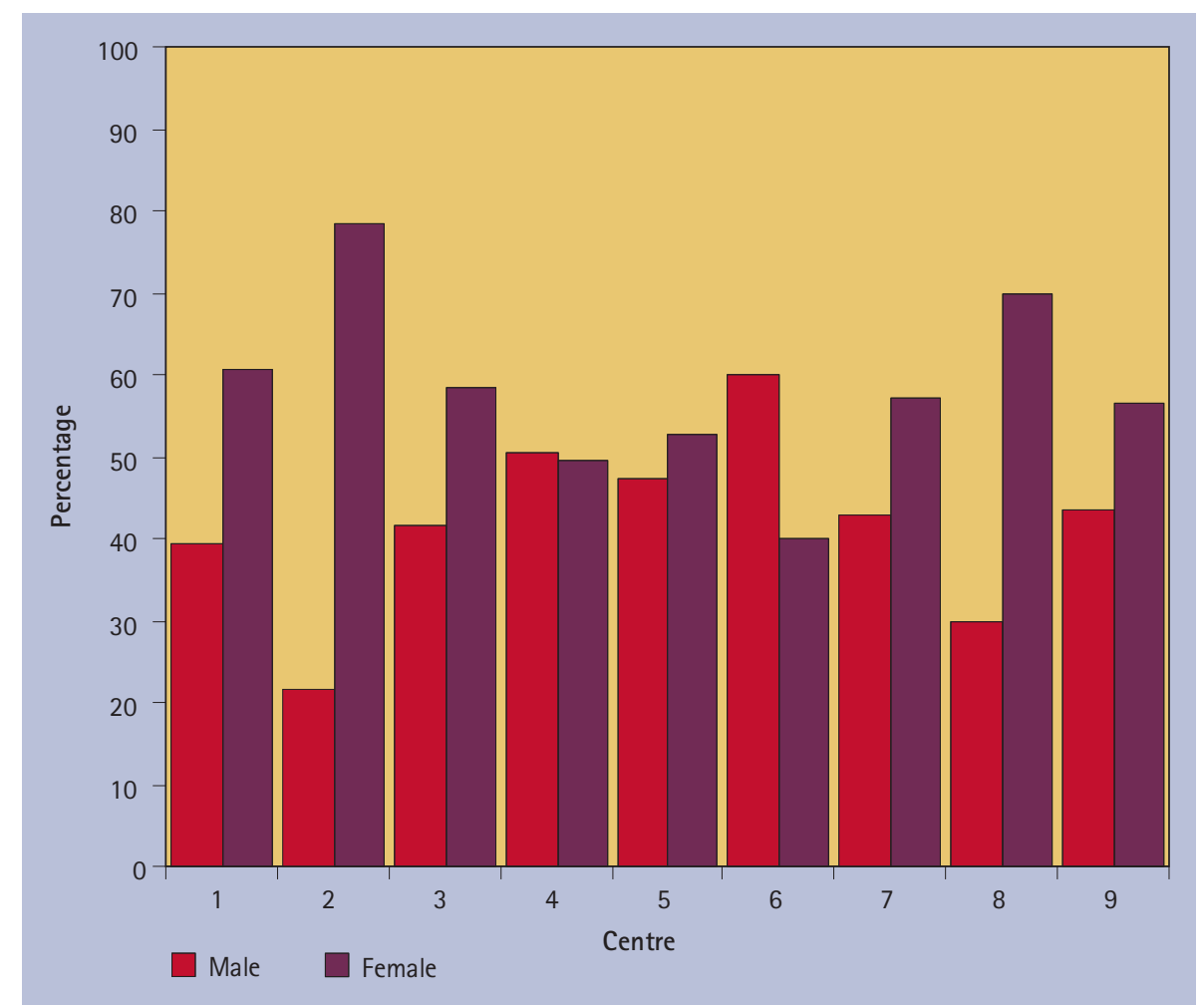

Fig. 3 Sex distribution

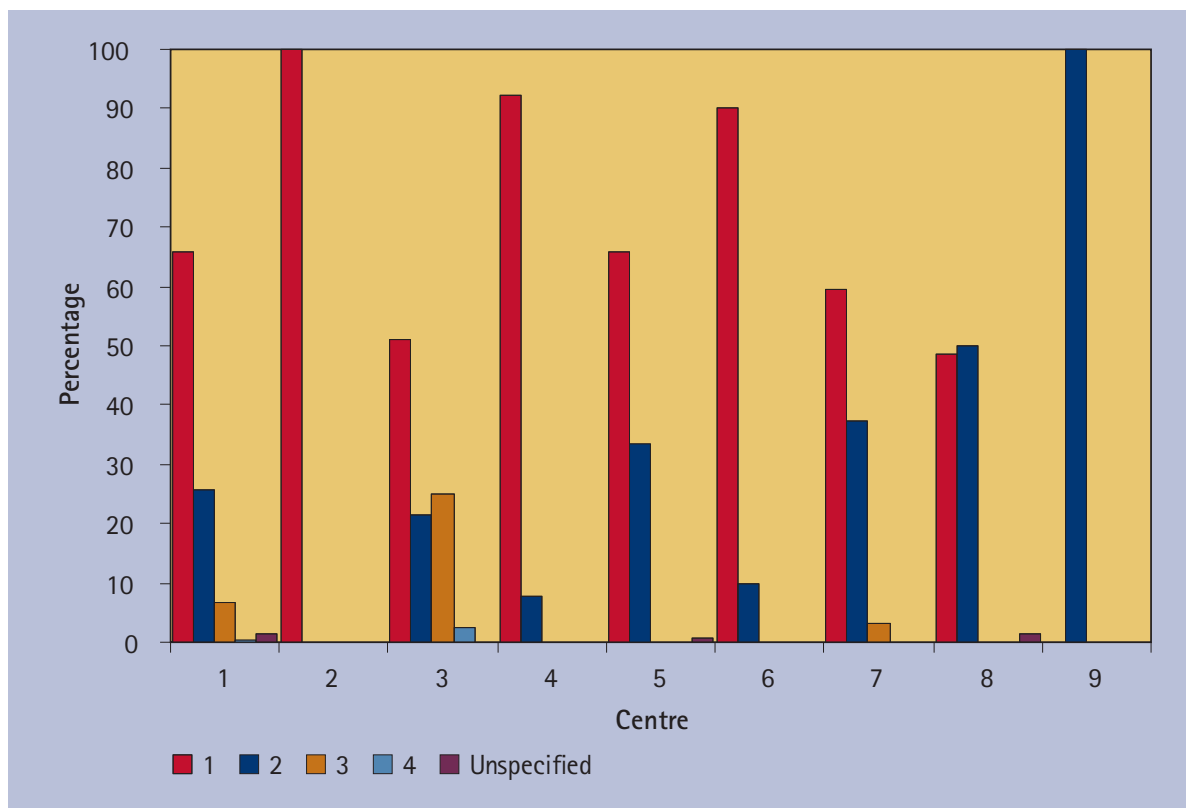

Fig. 4 ASA grades

within the CDS (544 sedation episodes). A total of 392 sedation episodes (38\%) were undertaken in the two HDS centres; while the remaining 101 sedation episodes (10\%) were undertaken in the single GDS centre (see Table 1 and Fig. 1).

\section{Age range}

In general, the GDS and CDS treated a younger group of patients than the HDS. The age range of patients treated in the CDS centres was 5-79 years, with

\section{ASA grades}

The majority of patients treated in the GDS (93) were in ASA 1 category (92\%), with the remainder (8) belonging to ASA 2 category. Similarly, most patients treated in the CDS were in ASA 1 (59\%) and ASA 2 (39\%) categories.

In contrast, 11\% (42) of the patients in the HDS centres belonged to ASA 3 category. However, the majority were in ASA 1 (63\%) and ASA 2 (25\%) categories (Fig. 4).

\section{Type of sedation}

Overall, IHS comprised 68\% and IVS comprised $32 \%$ of the sedation techniques used in the GDS. Similarly, IHS comprised 60\% and IVS comprised $28 \%$ of the sedation techniques used in the CDS.

The majority (61\%) of the sedation type in the HDS centres were IVS ( $\mathrm{n}=238$ ). IVS was used in combination with IHS, oral sedation (OS) or transmucosal/intranasal (TMS) in many cases (Fig. 5). However, it was not possible to ascertain these numbers due to the inflexibility of the software in one centre to allow two values to be entered for a single patient in this category.

\section{Completion of planned episode of treatment}

All centres offered the full range of treatment including restorative treatment. This was confirmed with all the service providers.

In the GDS centre, 100 (99\%) planned episodes of treatment were completed, while one (1\%) was not. In the CDS, a total of 525 planned episodes of treatment were completed (96.5\%); while 16 could not be completed (3\%). Three episodes were not specified (0.5\%). Among the HDS centres, 344 (88\%) planned episodes of treatment were completed, while $44(12 \%)$ were not. One $(0.3 \%)$ result was unspecified (Fig. 5).

Overall, the range of completion rate for all nine centres was $86 \%$ to $100 \%$, with a mean of $92 \%$.

\section{Adverse incidents}

Information regarding adverse incidents was recorded as free comment by individual participating centres. No adverse incidents were reported from the GDS clinic. A total of 35 adverse incidents were reported from the CDS clinics (6\%). The HDS clinics 
reported a total of five adverse incidents (1.3\%) (see Fig. 6). Some centres, however, were unable to record details regarding adverse incidents due to difficulties in entering information into their databases set up by their IT departments.

Overall, the range of adverse incidents for all nine centres was $1.2 \%$ to $13 \%$, with a mean of $2.6 \%$. This exceeded the standard of $2 \%$ set for this audit. However, a closer examination of the adverse incidents revealed several that were inappropriate for inclusion. This is explored further in the Discussion.

\section{Fasting}

Patients in the GDS and CDS centres did not fast before the sedation episodes. In the HDS centres, $2-10 \%$ of patients fasted. The routine advice to patients at both HDS centres was to eat a light meal up to two hours before the sedation appointment. However, some patients who were obese were advised to fast. Centres 5 and 7 did not record this data.

\section{DISCUSSION}

A network of sedation practitioners comprising the GDS, CDS and HDS was formed in South and West Wales. This multi-centre prospective audit aimed to compare the safety and predictability of dental treatment with conscious sedation. Through this process, it was proposed to establish a baseline of current practice in relation to conscious sedation and facilitate clinical governance.

The reason for providing sedation was not recorded as part of this audit. However, anecdotally, the vast majority of patients treated required sedation to manage fear/anxiety in relation to dental treatment. Results from a large telephone survey conducted by Goodwin and Pretty (2011) comprising 12,002 interviews concluded that one of the top reasons for non-attendance for dental treatment was fear/anxiety. It is estimated that sedation need could rise to $6.9 \%$ of the population, if extended to include nonattending patients with high levels of anxiety. ${ }^{12}$ The IOSN ${ }^{13}$ (Index of Sedation Need) has been developed and validated as an assessment tool. This potentially could aid decision making and referral management. In addition, it could be used by commissioners in order to plan, commission and deliver appropriate sedation services.
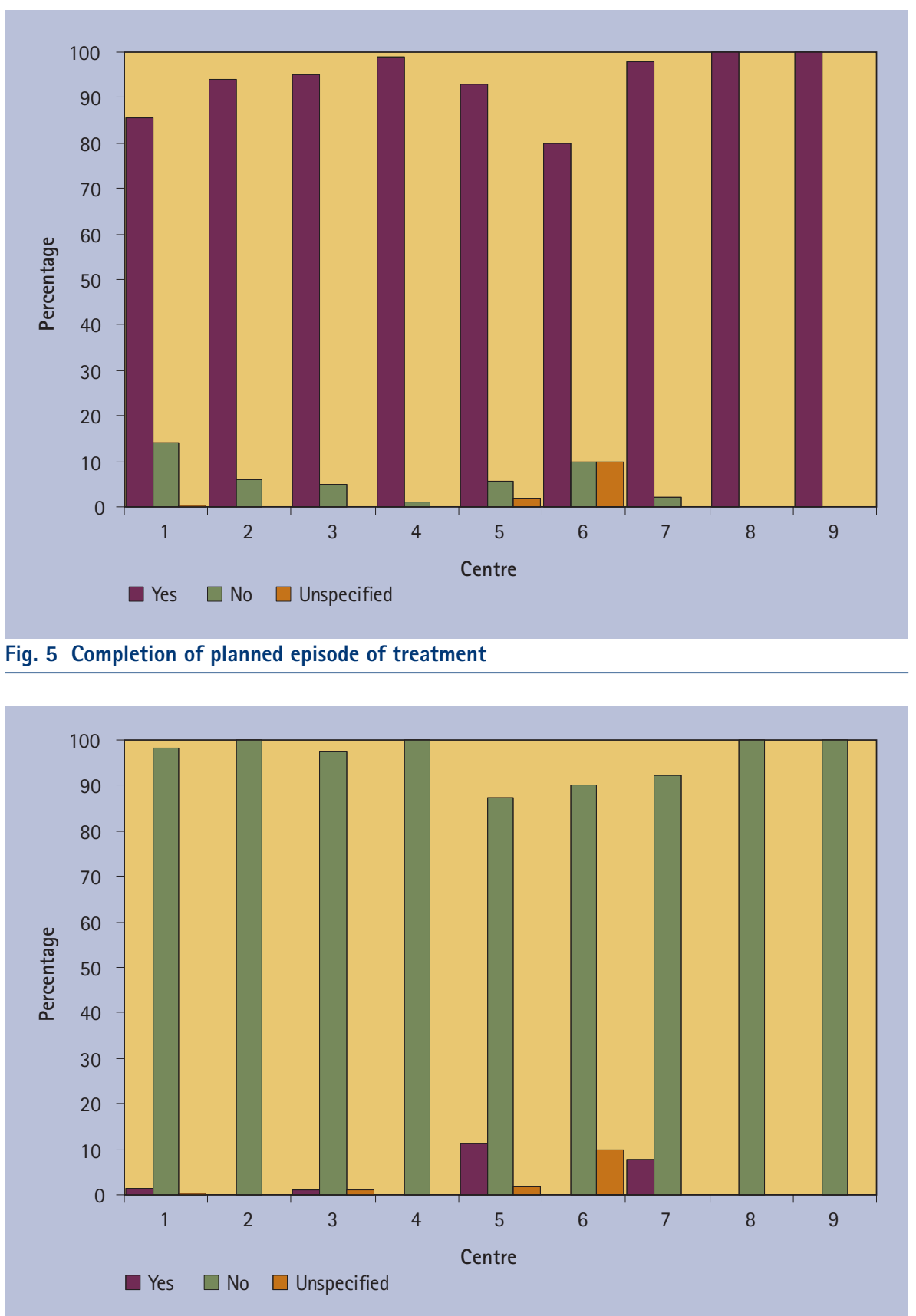

Fig. 6 Adverse events

The dentists who contributed to this multi-centre regional audit wanted to be proactive about maintaining standards in the practice of conscious sedation in dentistry. The preliminary aim of this particular network was to facilitate clinical governance among practitioners of conscious sedation in dentistry in South and West Wales, primarily by participation in multi-centre regional audit. 'Clinical governance' describes the structures, processes and culture needed to ensure that healthcare organisations and all individuals within them can assure the quality of care they provide and are continuously seeking to improve it. ${ }^{14}$
Managed clinical networks (MCNs) are currently being developed in Wales as part of the special care dentistry implementation plan. ${ }^{15}$ Similar networks could be used to enable multi-centre audits, service evaluation and research in the future. A recent editorial in the Journal of Disability and Oral Health exhorted the need for research driven by such local networks:

'there is an urgent need to develop research skills within the dental team working at the sharp end. One way of doing this in the short term might be to develop local research networks supported by research mentors and regional research 


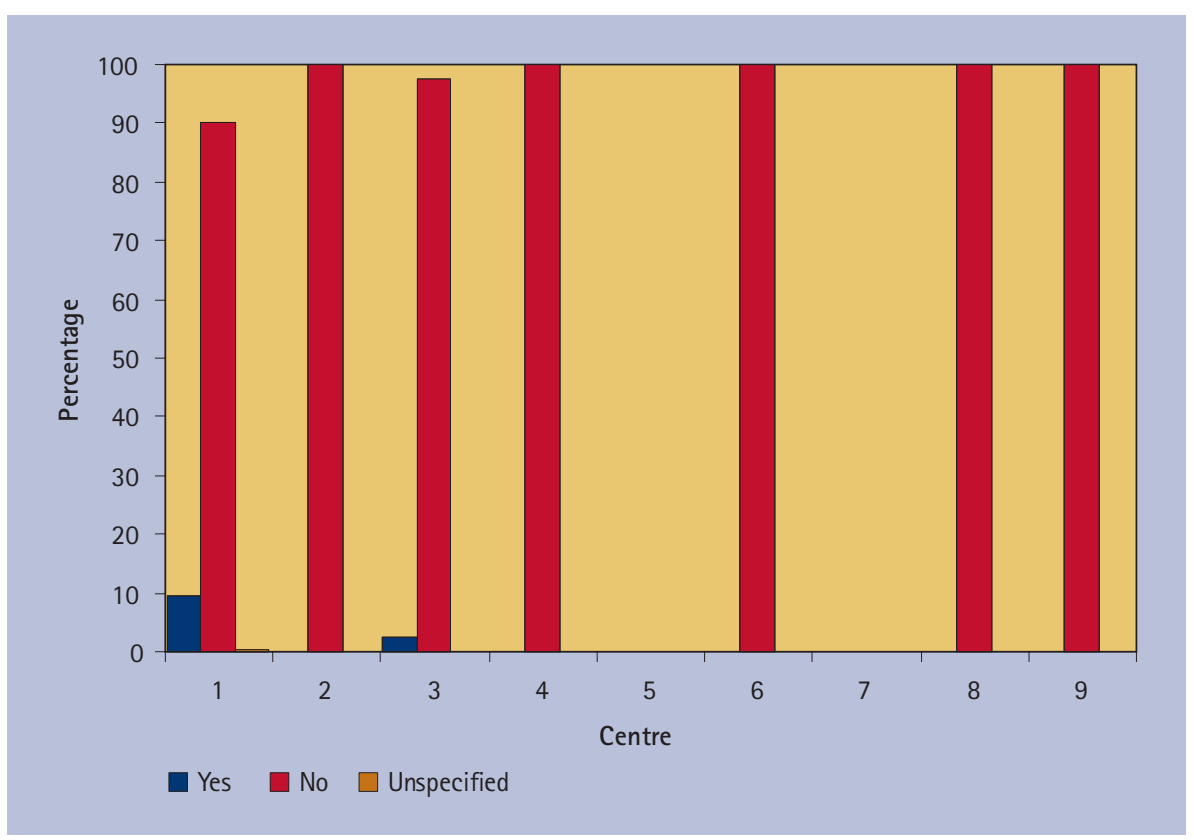

Fig. 7 Fasting

coordinators from among the BSDH membership. Developing local research networks among clinical practitioners is a model that has been used successfully in Scandinavia, the US (Pearl, PBRN, NW Precedent networks) and in the UK (Faculty of General Dental Practice). Local established networks could be the place to initiate clinical research networks. ${ }^{16}$

All practitioners in this audit already collected data of their own sedation activity as part of their individual clinical governance. However, as with any voluntary reporting system, the data is subject to bias. Interpretation of the data should therefore be undertaken with caution.

\section{Distribution of sedation activity across the dental services}

Few studies have investigated the availability of sedation services in dental practice in the UK. ${ }^{17,18}$ A questionnaire survey of primary care dentists in Wales in 2006 reported that only $12 \%$ provided some form of sedation. ${ }^{19}$

In the current audit, the majority (52\%) of dental treatment with conscious sedation was undertaken in the CDS. Interestingly, nearly 10\% was undertaken in a single GDS practice that had a sedation contract with the local health board. Unfortunately, despite efforts at the start of the survey to identify and contact all sedation practitioners in the area, some could not be identified at the start of this audit, and therefore did not contribute. In future audits participating audit members should facilitate knowledge of local sedation practitioners commissioned through their health boards.

\section{Age range}

The CDS generally treated patients of a younger age group, reflecting the patient population distribution within this service.

An ageing population maintaining their natural dentition is reflected by the inclusion in the upper end of the age distribution (79 years) in this audit. Interestingly, $38(3.6 \%)$ patients were aged 60 years or above; 26 (2.5\%) of these patients received IVS. Only 8 patients were aged 70 years or above in the overall figures. All patients in the $70+$ age group were treated with IHS only.

A total of 13 patients (1.2\%) of the over 60 years age group were treated in the CDS; 8 patients were treated with IVS. This could be interpreted as another reflection of the patient demographic and treatment provision in the CDS or it may reflect local policy in relation to older people.

\section{Sex}

There were 1.4 times more female patients than male in the current audit. This is in keeping with the findings of Pretty et al. (2011) that females were 4 times more likely than males to be anxious in relation to dental treatment and 6 times more likely than males to need sedation. ${ }^{20}$

\section{ASA grades}

Patients in ASA grade 3 should be referred to an appropriate secondary care unit. ${ }^{1,2}$ The practitioners in this dataset were compliant with this recommendation. Nearly all patients of ASA 3 grade were treated in the Hospital Dental Services.

\section{Type of sedation}

NICE guideline 112 recommends the use of nitrous oxide or midazolam for a child or young person who cannot tolerate a dental procedure with local anaesthesia alone. ${ }^{21}$ As the GDS and CDS treat the majority of patients in these age groups, IHS would appear to have been appropriately used for most patients in this group. Additionally, patients in the over 70 year age group were treated with IHS only. This could be a reflection of the caution exercised by operators due to the potential for increased morbidity in the older age groups.

Future surveys should aim to correct deficiencies in data collection so that combination techniques or multiple drug techniques can be recorded accurately.

\section{Completion rate}

Interestingly, some practitioners in the group interpreted 'completion' as completion of a course of treatment; and therefore may have given a lower completion rate. A more accurate description for completion rate should have been the completion of a planned treatment, for that particular treatment episode.

In the GDS centre, 100 (99\%) episodes of planned treatment were completed. Assessments and treatments in this centre were undertaken by a single general dental practitioner (GDP), possibly indicating the advantages of maintaining continuity and rapport with patients. In other centres where assessments and treatments may be undertaken by multiple practitioners, poorer completion rates may be evident.

The data from this audit suggests that in $8 \%$ of patients, the planned episode of treatment could not be undertaken with conscious sedation. However, within the limitations of this audit, it was not possible to infer if other forms of sedation were used subsequently or with a more experienced operator; or if general anaesthesia (GA) was used.

Guidelines from the General Dental Council (2000), the Department of Health 
(2000) and the Standing Dental Advisory Committee (2003) have stressed the appropriate use of general anaesthesia, and advise the adoption of alternative techniques such as conscious sedation. ${ }^{22,41}$

\section{Adverse incidents}

No attempt was made within the network to define an adverse event or classify its seriousness before the audit. The NPSA classifies harm as 'No harm', 'Low harm', 'Moderate harm', 'Severe harm' and 'Death' (see Table 2). ${ }^{23}$

Based on the NPSA classification of harm, the following reported events may be regarded as 'no harm':

- 'non-compliant, refused treatment'

- 'would not allow treatment'

- 'could not breathe through nose'

- 'consent issue'

- 'obese, poor veins'

- 'hyperventilating, panicking'

- 'DNA'.

The following events may be regarded as 'low harm':

- 'suffered flashback to previous episode, became distressed, sedation reversed'

- 'patient not sedated on $9 \mathrm{mg}$ midazolam. Admitted to using $30 \mathrm{mg}$ diazepam routinely and other drug use'

- 'desaturated, supplemental oxygen needed, flumazenil reversal'

- 'desaturated, supplemental oxygen needed'

- 'oversedation, supplemental oxygen given'.

One incident that was related to local anaesthesia and not to the sedation may be regarded as 'moderate harm' based on this classification: 'patient had facial palsy with drooping lip on RHS. Unable to close Rt eyelid after injection - decided to stop and refer for assessment'.

No attempt was made to define desaturation before the audit. Desaturation would appear to have been defined differently in various publications. Wood (2011) described desaturation as a 5\% drop from baseline $^{6}$ while, Manley and colleagues (2010) have used a criterion of the oxygen saturation being repeated below 90\% to define desaturation.?

A retrospective study by Viljoen (2011) of oxygen saturation in 3,500 cases of sedation

\section{Table 2 Definitions of degree of harm (Source - NPSA 2006)}

\section{No harm}

Impact prevented: any patient safety incident that had the potential to cause harm but was prevented resulting in no harm to the person(s) receiving NHS-funded care.

Impact not prevented: any patient safety incident that ran to completion but no harm occurred to the person(s) receiving NHS-funded care.

Low harm

Any patient safety incident that required extra observation or minor treatment, and caused minimal harm to the person(s) receiving NHS-funded care.

Moderate harm

Any patient safety incident that resulted in a moderate increase in treatment, and which caused significant but not permanent harm to the person(s) receiving NHS-funded care.

Severe harm

Any patient safety incident that resulted in permanent harm to the person(s) receiving NHS-funded care. Death

Any patient safety incident that directly resulted in the death of the person(s) receiving NHS-funded care.

carried out by a single operator sedationist in a dental private practice setting, reported 25 oxygen desaturation readings out of a total of 3,500. ${ }^{24}$ Oxygen desaturation was defined as any pulse oximeter reading less than 94\%. However, patients were administered a combination of midazolam and fentanyl with or without additional propofol. This would be considered an alternative sedation technique in dentistry in the UK. ${ }^{25}$

The NPSA Rapid Response report (2008) on reducing the risk of overdose with midazolam injections in adults provides examples of incidents related to sedation ranging from 'deep sedation' where the patient was not arousable, to death. ${ }^{26}$ However, it does not specifically refer to oxygen saturation readings.

The paediatric research consortium reported on adverse events in the USA (2006). ${ }^{27}$ Serious adverse events were rare in the institutions involved in the study; there were no deaths. Cardiopulmonary resuscitation was required once. Less serious events were more common with $\mathrm{O}_{2}$ desaturation below $90 \%$ for $>30$ seconds, occurring 157 times per 10,000 sedations. Stridor and laryngospasm both occurred in 4.3 times per 10,000 sedations.

Cote et al. (2000) reported on a critical incident analysis of 95 adverse sedation events in children in the USA. ${ }^{28}$ They categorised adverse events broadly as 'death', 'permanent neurological injury', 'prolonged hospitalisation without injury' and 'no harm'. Sixty of these resulted in death or permanent neurological injury. They also investigated the medications associated with adverse events finding association with drug overdose, combinations and interactions. ${ }^{29}$
A Cochrane review of sedation of children undergoing dental treatment (2012) ${ }^{30}$ commented that:

'It was apparent while carrying out this review that there were significant differences in techniques and drugs used between countries and regions. Studies can be loosely grouped into two types, those based on a "North American" model of sedation and those based on a more "European" model. The North American model was typified by use of multiple agents (including adjunctive nitrous oxide) at any age, the use of restraint and intent to induce a deeper level of sedation. The European model was typified by use of single agents (typically nitrous oxide or midazolam) with intent to induce lighter levels of sedation. This is most likely due to cultural and legal differences and needs to be considered when making recommendations for the most effective methods of conscious sedation.'

One of the learning points from this preliminary audit was the urgent need within the network to define an 'adverse event' and to classify its seriousness for clinical governance. The NPSA classification of harm may merit further research in the field of conscious sedation.

\section{Fasting}

Fasting was not defined for the purpose of this audit. None of the centres routinely advocated fasting before sedation. This is in keeping with the SDCEP guidance document. ${ }^{2}$ However, one centre advocated fasting for obese patients. Other patients, including those with an exaggerated gag reflex chose to fast. The issue of fasting requires further consideration in future audits and studies. 


\section{Costs}

Detailed cost analysis comparing sedation and general anaesthesia are available. ${ }^{31}$ These would suggest that provided minimum success rates are reached, then sedation, particularly in primary care by an operator sedationist costs less than general anaesthesia. NICE estimates the potential annual savings from using sedation, instead of general anaesthesia at £22.5 million per year. The completion rate in this audit would support the continued use of conscious sedation based on a costbenefit analysis.

\section{Predictability of treatment and consent}

The Department of Health outlines 12 key points of consent. ${ }^{32}$ The completion rate of dental treatment with conscious sedation can be a useful measure of predictability. Safety and predictability of a treatment form part of the discussion in relation to consent. This multi-centre audit supported both the safety and predictability of conscious sedation in relation to dental treatment in a variety of care settings.

\section{Limitations of this multi-centre audit}

The main limitations of this audit were:

- Limited dataset - not all sedation practitioners took part

- Lack of uniform training for data collection and entry - some of the data was collected by various practitioners including undergraduate and post graduate students

- Operational and logistic issues - both paper based and computer system were used

- Computers were not always accessible and some data entry systems were not user friendly.

One of the recommendations of the Welsh Dental Committee's report on special care dentistry in Wales is that 'appropriate IT systems should be developed for monitoring service provision and clinical governance. ${ }^{33}$

This is reiterated in the Welsh Assembly Government's Special Care Dentistry Implementation Plan: 'a common approach to data collection and defined processes to enable the transfer of essential information between organisations should be established to ensure patient needs are met.' ${ }^{15}$

\section{CONCLUSION}

Conscious sedation had a completion rate of $92 \%$ and a minor adverse incident rate of $2.6 \%$ in this multi-centre prospective audit. Completion of planned treatment is a good proxy for success of a technique. After all, the goal of treatment with conscious sedation is not determined by the quality of sedation, even though some studies dwell on this aspect of treatment.

Even though this audit was about conscious sedation, other techniques such as cognitive behavioural therapy (CBT), hypnosis and behaviour management also provide excellent results, depending on the patient's level of anxiety and the practitioners' skills. ${ }^{34}$

The group recommended the following, after a post-audit review meeting:

- Develop standardised data collection methods and software

- Define 'critical incident' and categorise adverse events in conscious sedation

- Repeat audit with refined audit tool including IOSN.

Large scale audits give an overview of clinical governance in relation to a variety of care settings; however, they cannot provide the details that would be derived from a well-planned research strategy. The audit demonstrated that conscious sedation was safe and predictable, provided patients were assessed adequately and that guidelines were followed.

The authors wish to thank the sedation practitioners, MSc students and sedation nurses for their invaluable contributions and data. This audit would not have been possible without their support. In particular, we would like to appreciate the efforts of David Davies, Eimear Rowan, Anthony Davies, Aisha Tahir, Sianed King, Sheila Oliver, Michael Allen, Vicki Jones and Helen Garside.

1. Standing Dental Advisory Committee. Conscious sedation in the provision of dental care: report of an expert group on sedation for dentistry. London: Department of Health, 2003. Online information available at http://webarchive. nationalarchives.gov.uk/+/www.dh.gov.uk/ en/Publicationsandstatistics/Publications/ PublicationsPolicyAndGuidance/DH_4069257 (accessed June 2013).

2. Scottish Dental Clinical Effectiveness Programme. Conscious sedation in dentistry. 2nd ed. Dundee: Scottish Executive and NHS Education for Scotland, 2012. Online information available at http://www.sdcep.org.uk/index.aspx?o=2331 (accessed June 2013).

3. Dental Sedation Teachers Group. Standards in Conscious Sedation for Dentistry. 2000. http://www.dstg.co.uk/ standards-in-conscious-sedation-for-dentistryl.

4. A Conscious Decision: A Review of the Use of General Anaesthesia and Conscious Sedation in Primary Dental Care. Report of a Group Chaired by the Chief Medical and Chief Dental Officer. Department of Health, 2000. Online review available at http://webarchive. nationalarchives.gov.uk/+/www.dh.gov.uk/ en/Publicationsandstatistics/Publications/ PublicationsPolicyAndGuidance/DH_4074702 (accessed June 2013).

5. Blain K M, Hill F J. The use of inhalation sedation and local anaesthesia as an alternative to general anaesthesia for dental extractions in children. Br Dent J 1998; 184: 608-611.

6. Wood M. The safety and efficacy of using a concentrated intranasal midazolam formulation for paediatric dental sedation. SAAD Dig 2011; 27: 16-23.

7. Manley M C G, Ransford N J, Lewis D A, Thompson $S$ A, Forbes M. Retrospective audit of the efficacy and safety of the combined intra-nasal and intravenous midazolam sedation technique for the dental treatment of adult with learning disability. Br Dent J 2008; 205: E3.

8. Muller S, Prolla J C, Maguilnik I, Breyer H. Predictive factors of oxygen desaturation of patients submitted to endoscopic retrograde cholangiopancreatography under conscious sedation. Arq Gastroentero/ 2004; 41: 162-166.

9. Rozario L, Sloper D, Sheridan M J. Supplemental oxygen during moderate sedation and the occurrence of clinically significant desaturation during endoscopic procedures. Gastroenterol Nur 2007; 31: 281-285.

10. Hardeman J H, Sabol S R, Goldwasser M S. Incidence of hypoxaemia in the post-anaesthetic recovery room in patients having undergone intravenous sedation for out-patient oral surgery. J Oral Maxillofac Surg 1990; 48: 942-944.

11. What is clinical audit? Healthcare Quality Improvement Partnership. Online information available at http://www.hqip.org.uk/ what-is-clinical-audit (accessed June 2013).

12. Goodwin M, Pretty I A. Estimating the need for dental sedation. 3. Analysis of factors contributing to non-attendance for dental treatment in the general population, across 12 English Primary Care Trusts. Br Dent J 2011; 211: 599-603.

13. Coulthard $P$, Bridgman C M, Gough L, Longman $L$, Pretty I A, Jenner T. Estimating the need for dental sedation. 1. The Indicator of Sedation Need (IOSN) - a novel assessment tool. Br Dent J 2011; 211: E10.

14. Department of Health. Clinical governance guidance. 2011. Online information available at http: //www.dh.gov.uk?health/2011/09/clinicalgovernance (accessed December 2012)

15. Welsh Assembly Government. Special Care Dentistry in Wales implementation plan. November 2011. Online information available at http://www.wales.nhs.uk/documents/SCD\%20 Implementation\%20Plan\%2OFINAL\%20 VERSION2\%2011\%2011\%20(2).doc (accessed June 2013).

16. Daly B. Research in special care dentistry. Editorial. J Disability Oral Health 2011; 12: 146-147.

17. Whiston S, Prendergast M J, Williams S A. Sedation in primary dental care: an investigation in two districts of Northern England. Br Dent J 1998; 184: 390-393.

18. Foley J. The way forward for dental sedation and primary care? Br Dent J 2002; 193: 161-164.

19. Chadwick B, Thompson S, Treasure E T. Sedation in Wales: a questionnaire. Br Dent J 2006; 201: 453-456.

20. Pretty I A, Goodwin M, Coulthard P et al. Estimating the need for dental sedation. 2. Using IOSN as a health needs assessment tool. Br Dent J 2011; 211: E11.

21. Sedation in children and young people. NICE clinical guideline 112. London: National Clinical guideline centre, 2010. http: //www.nice.org.uk/ CG112.

22. General Dental Council. Standards for dental 
professionals. London: General Dental Council, 2005. Online information available at http://www. gdc-uk.org/Newsandpublications/Publications/ Publications/StandardsforDentalProfessionals\%5B 1\%5D.pdf (accessed June 2013).

23. With safety in mind: mental health services and patient safety. Patient safety observatory report 2 (0294). NHS National Patient Safety Agency, 2006 Online report available at http://www.nrls.npsa. nhs.uk/resources/collections/pso-reports (accessed June 2013).

24. Viljoen A, Byth K, Coombs M, Mahoney G, Stewart D. Analysis of oxygen saturations recorded during dental intravenous sedations: A retrospective quality assurance of 3: 500 cases. Anesth Prog 2011; 58: 113-120.

25. Standards for conscious sedation in dentistry. alternative techniques. A report of the Standing Committee on Sedation for Dentistry, 2007. Online report available at http://www.rcseng.ac.uk/fds/ publications-clinical-guidelines/docs/SCSDAT\%20 2007.pdf/view (accessed June 2013).

26. Rapid response report: NPSA/2008/RRR011.
Reducing risk of overdose with midazolam injection in adults. NHS National Patient Safety Agency, 2008. Online report available at http:// www.nrls.npsa.nhs.uk/EasySiteWeb/getresource. axd?AssetID=60299 (accessed June 2013).

27. Paediatric sedation research consortium. Incidence and nature of adverse events of adverse events during paediatric sedation/ anaesthesia for procedures outside the operating room: report from the paediatric sedation research consortium Paediatrics 2006; 118: 1087-1096.

28. Cote C J, Notterman D A, Karl H W, Weinberg J A, McClosey C. Adverse sedation events in paediatrics: a critical incident analysis of contributing factors. Paediatrics 2000; 105: 805-814.

29. Cote C J, Karl H W, Notterman D A, Weinberg J A, McCloskey C. Adverse sedation events in paediatrics: analysis of medications used for sedation. Paediatrics 2000; 106: 633-644.

30. Lourenço-Matharu L, Ashley P F, Furness S. Sedation of children undergoing dental treatment Cochrane Database Syst Rev 2012; 3: CD003877.

31. NICE. Sedation in children and young people. Costing report: implementing NICE guidance. NHS National Institute for Health and Clinical Excellence, 2010. Online report available at http://www.nice.org.uk/nicemedia/ live/13296/52185/52185 (accessed June 2013).

32. Good practice in consent implementation guide: consent to examination or treatment London: Department of Health, 2001. Online information available at http://webarchive. nationalarchives.gov.uk/+/www.dh.gov.uk/ en/Publicationsandstatistics/Publications/ PublicationsPolicyAndGuidance/DH_4005762 (accessed June 2013).

33. Welsh Dental Committee special care dentistry sub-group. Report on special care dentistry in Wales: review and recommendations. June 2010. Online report available at http://www.wales.nhs.uk documents/FINAL\%20Report\%20For\%20WDC\%20 12\%207\%20101.pdf (accessed June 2013).

34. Newton T, Asimakopoulou K, Daly B, Scambler S, Scott $\mathrm{S}$. The management of dental anxiety: time for a sense of proportion? Br Dent J 2012; 213: $271-274$. 